\title{
Main Nuances of the Selection of a Gas Boiler for a Heat Supply System
}

\author{
Kabanov Oleg Vladimirovich, Ogarev Mordovia State University, Russia, Republic of Mordovia, Saransk, Bolshevitskaya Street.
}

Panfilov Stepan Alexandrovich, Ogarev Mordovia State University, Russia, Republic of Mordovia, Saransk, Bolshevitskaya Street.

Vorontsov Evgeniy Anatolievich, Moscow State University of Civil Engineering, Russia, Moscow, Yaroslavskoye Shosse.

Avlasevich Alexander Ivanovich, Siberian Federal University, Russia, Krasnoyarsk, Svobodny pr.

Grigoryev Andrey Anatolievich, Peter the Great Saint Petersburg Polytechnic University, Russia, Saint-Petersburg, Plytechnicheskaja.

Pahov Yuri Mikhailovich, Griboyedov Institute of International Law and Economics, Russia, Moscow, sh. Enthusiasts.

\begin{abstract}
Gas heating has long been firmly in the leading position among all types of Autonomous heating systems. However, despite its wide popularity, manufacturers are constantly developing and implementing new, technologies that are more effective. In addition, there are many brands and even more varieties and models of gas boilers. This article will provide comprehensive information about the features of gas heating in a private home: criteria for choosing boilers, advantages and disadvantages of various types of gas boilers.
\end{abstract}

Keywords--- Gas Boiler, Heat Exchanger, Heating, Power, Gas.

\section{Introduction}

The cheapest type of fuel today is gas, and, probably, few will argue with this [1]. The advantages that the user receives by installing a huge number of gas boilers in his house as the main source of heating, we note the main ones: heating quality, uninterrupted operation, economy, efficiency [2-4]. That is why we can say with confidence that gas boilers are a profitable purchase if the house is gasified. Today, various manufacturers offer this type of equipment in a large assortment, which allows everyone to buy a unit that meets the requirements and is ideally suited for operation in specific conditions $[5,12,13]$. Consider the main points that should be considered when choosing a gas boiler. The choice of gas equipment regarding power. The boiler power is one of the important parameters on which not only the efficiency and quality of the heating system will depend, but also its efficiency. The power of the device is determined based on the area of the heated room. Note that if the capacity is insufficient, then the heating will be of poor quality, the temperature in the rooms will be low, while the fuel consumption will be high. If you buy a boiler of greater power, you will have to constantly adjust the heating temperature of the coolant, with such work, fuel consumption will be high. Therefore, when choosing, it is important to know that $1 \mathrm{~kW}$ of power is needed per $10 \mathrm{~m}^{2}$, it turns out that for a house with an area of $150 \mathrm{~m}^{2}$, the minimum power of the unit should be $15 \mathrm{~kW}$, provided that the house is well insulated, but even so, experts recommend adding 10 to the obtained value $\%$ on possible heat loss. When determining the required capacity of a gas boiler, one should take into account: the quality of the house's insulation, as well as what materials it is built from, the height of the ceilings, as well as the number and size of windows in the house and in each room separately, the climatic conditions of the region $[6,7,8,14]$.

The choice of a gas boiler with respect to the method of adjusting power. Today, manufacturers of this type of equipment offer models with three options for adjusting power: single-stage, two-stage, with smooth adjustment. Consider each option individually. So, single-stage gas boilers are among the simplest heating equipment. This type of equipment is perfect for use in small houses. After installation, the wizard makes certain settings, sets the required power, etc., after which you can start operating the device. Two-stage boilers are characterized by a complex adjustment system, which allows you to quickly and easily change the power of the boiler to heat depending on weather changes. The question arises, which of the options is better to install in the heating system of your home? It is impossible to answer the question unequivocally, since each of the options differs in its advantages and disadvantages. However, experts recommend two-stage gas boilers, with which it is possible to decently save on fuel consumption during the operation of the device. Such boilers are able to create the most comfortable conditions for living in the house, regardless of the air temperature in the street. Gas burner and boiler heat exchanger. It is quite difficult to understand all the details of the operation of the equipment, as well as its structural elements. In any 
heating equipment, a heat exchanger is installed through which the heat carrier passes and heats up to a certain temperature. The service life, as well as the stability and quality of the boiler, depends on the materials used in the production. The following types of heat exchangers are installed in gas boilers: - copper. Install mainly in wall mounted gas appliances. Their main advantage is durability, corrosion resistance, lightness and flexibility; - steel. They are installed in floor heating boilers, more often in inexpensive appliances. Benefits include strength, ductility and flexibility. As for the disadvantages, the steel heat exchangers are susceptible to corrosion, which significantly reduces the durability index; - cast iron. Are established in gas floor coppers, differ in durability, resistance to corrosion. A distinctive feature of cast-iron heat exchangers is the ability to heat up quickly. Now a few words about the combustion chamber and the burner. The quality of these structural elements determines the efficiency, safety and reliability of the unit. Today, devices with an open and closed combustion chamber are offered. Models of the first type are simple in design, the air intake required for burning the incoming fuel is carried out from the room in which the boiler is installed. Boilers with a closed chamber are connected to a coaxial chimney through which combustion products are discharged through the inner pipe and air is supplied to the combustion chamber through the outside. The choice of a gas boiler in relation to the number of circuits. There are two types of boilers, namely single-circuit and double-circuit. In the first case, the equipment heats the water only circulating through the heating pipes. In the second case, in addition to heating the coolant, the devices are able to provide the GWS user.

As for the choice of a single-circuit model, everything is simple here, we determine the power of the device based on the area of the house, how to do it is described above. It is more difficult to determine the choice of a double-circuit boiler, it is important to consider how much hot water is required to meet every day needs. Note that a gas double-circuit boiler with a capacity of $25-30 \mathrm{~kW}$ is able to provide the user with hot water in the amount of 15 liters per minute. The indicator is simply excellent, but as practice shows, today with the advent of various household equipment this may not be enough. What to do in this case? The easiest way is to buy a storage tank with a volume of 80-100 liters, which can provide the required amount of hot water.

All the above features of boiler equipment should be fully reflected in the design solution of the heat supply system. That is, everything should be taken into account already when the design of the heating system occurs [9, $10,11]$. Only the presence of a technically competent and reasonable design of engineering systems for a residential building under construction is the main guarantee of the absence of problems for its owner in the future.

\section{References}

[1] Orlov M. O. Household gas appliances. Tutorial. / M.O. Orlov. // - 2012. - 10-13 p.

[2] Pozdnyakov A. V. Gas water heating boiler for heating a house / A. V. Pozdnyakov. // 2016.- 22-23 p.

[3] Dorokhova, M. A. Electricity, water supply and heating in your home. / M.A. Dorokhov, Erokhin. P.V. // 2009. - 62 p.

[4] Krupnov, B. A. Guidelines for the design of heating, water supply and air conditioning systems. / B. A. Krupnov, Sharafadinov, N. S. // 2005. -152-153 p.

[5] Aleksandrovich, P.S., Vladimirovich, K.O. Determination of thermal-physical properties of facilities. 2016, Journal of Engineering and Applied Sciences 11(13), pp. 2925-2929

[6] Alexandrovich, P.S., Andreevich, F.Y., Vladimirovich, K.O. Thermal mode calculation tecnique for thermal syphone with two-component heat carrier. 2017, Journal of Engineering and Applied Sciences 12 (Specialissue2), pp. 6335-6338

[7] Alexandrovich, P.S., Vladimirovich, K.O. Method of a building object thermophysical property determination. 2017, Journal of Engineering and Applied Sciences 12(Specialissue 11), pp. 9056-9060

[8] Alexandrovich, P.S., Vladimirovich, K.O. Autonomous power supply system for lighting equipment. 2017, Journal of Engineering and Applied Sciences 12(Specialissue10), pp. 8954-8958

[9] Vladimirovich, K.O., Igorevna, S.O., Abdulazizovna, I.D. Experimental installation to determine the heat loss of a construction object. 2019, Test Engineering and Management 81(11-12), pp. 1811-1815

[10] Vladimirovich, K.O., Aleksandrovich, P.S., Alexandrovich, P.A., Sergeevna, S.E. Measuring the thermo physical properties of construction projects. 2019, Journal of Computational and Theoretical Nanoscience 16(7), pp. 3121-3127

[11] 11.Vladimirovich, K.O., Aleksandrovich, P.S., Alexandrovich, P.A., Sergeevna, S.E. Automated portable installation to determine the thermo physical properties of the object. 2019, Journal of Computational and Theoretical Nanoscience 16(7), pp. 3115-3120

[12] Vladimirovna, L.A., Vladimirovich, K.O., Mordovia, O. Energy-efficient autonomous system of heating 2019. Journal of Computational and Theoretical Nanoscience 16(1), pp. 145-150 
[13] Vladimirovna, L.A., Vladimirovich, K.O., Viktorovich, M.V. Conducting audits in small enterprises and assessing their compliance with international standards. 2019, Journal of Critical Reviews 6(4), pp. 79-83

[14] Sergeevna, S.E., Vladimirovich, K.O., Anatolievich, G.A. Features of the use of testing as a method of pedagogical control of students' knowledge in the educational process. 2020, Journal of Critical Reviews 7(3), pp. 181-184. 